\title{
Leonardo da Vinci and the Insulin Experience
}

\author{
Sanjay Kalra ${ }^{1}$ and Banshi Saboo ${ }^{2}$ \\ 1. Department of Endocrinology, Bharti Hospital, Karnal, India; 2. Department of Diabetology, DiaCare Hospitals, Ahmedabad, India
}

DOl: https://doi.org/10.17925/USE.2018.14.2.56

T his editorial is based on the philosophy of Leonardo da Vinci, the great maestro, and its relevance to insulin use. We use the basic principles of scientific thought that he practiced to address a major clinical challenge today: the suboptimal insulin experience. The seven cardinal principles of da Vinci: curiosita, dimostrazione, senzazione, sfumato, arte/scienza, corporalita and connessione are applicable to insulin usage as well. This editorial discusses these principles and their concordance with various therapeutic models and frameworks. These include therapeutic patient education, injection technique, diabetes-friendly healthcare, user-friendly delivery devices, the biopsychosocial model, patient-centred care, diabetes therapy by the ear and motivational interviewing. The need to improve insulin literacy and numeracy, teach injection technique with user-friendly delivery devices, and address insulin distress is articulated. The importance of continuing medical education, learning from experience, following a healthy lifestyle and preventing compassion fatigue is discussed.

\section{Keywords}

Clinical inertia, communication, diabetes, diabetes distress, insulin, insulin inertia, insulin motivation, type 2 diabetes

Disclosure: Sanjay Kalra and Banshi Saboo have nothing to disclose in relation to this paper.

Review Process: This is a short opinion piece and as such has not undergone the journal's usual peer review process but has been approved by the editorial board.

Authorship: All named authors meet the International Committee of Medical Journal Editors (ICMJE) criteria

for authorship of this manuscript, take responsibility for the integrity of the work as a whole, and have given final approval to the version to be published.

open Access: This article is published under the creative Commons Attribution Noncommercial License, which permits any noncommercial use, distribution, adaptation, and reproduction provided the original author(s) and source are given appropriate credit. (C) The Authors 2018

Received: June 21, 2018

Published Online: July 13, 2018

Citation: US Endocrinology, 2018;14(2):56-8

Acknowledgments: We acknowledge the inspiration and guidance we have received from the beautifully written book Think Like da Vinci. ${ }^{2}$

Correspondence: Sanjay Kalra, Department of Endocrinology, Bharti Hospital, Karnal, India. E: bridekn|@gmail.com

Support: No funding was received for the publication of this article.
The year 2019 is special. It marks the anniversary of two events: one a beginning, the other an end. While the beginning signals an end, the end represents a beginning as well. Both events have influenced humankind immensely; both deserve to be remembered and celebrated. The first event took place 500 years ago, on 2 May 1519, when an Italian named Leonardo passed away at the age of $77 .{ }^{1}$ Though this was the end of a lifetime, it also opened the doors for future painters, philosophers, engineers and scientists to build on his work. Leonardo da Vinci began the modern scientific thought process, ${ }^{2}$ which continues even after his death.

The second event occurred 400 years later, when 11-year-old Elizabeth Hughes was diagnosed to have diabetes. She would go on to become the first American to receive insulin. ${ }^{3}$ The beginning of insulin was thought to be the end of diabetes. In Elizabeth's case, the beginning of diabetes was also the beginning of a new era in American medicine. Though insulin did not (and has not) been able to cure diabetes, it did create miracles. One of these was the long life of Elizabeth Hughes (1907-1981).

\section{The current challenge}

Diabetes continues to explode worldwide. ${ }^{4}$ Unfortunately, uncontrolled diabetes continues to grow as well, and recent data reveal that, on average, glycaemic control in USA has worsened over the past decade. ${ }^{5}$ This is surprising, given the immense advancement in diabetes pharmaco-therapeutics and delivery. One way of overcoming this challenge, may be to utilize Leonardo da Vinci's thought process in creating strategies to manage diabetes.

\section{The da Vincian philosophy}

Leonardo da Vinci, the famous Italian scholar, is widely regarded as the most brilliant human mind of all time. Da Vinci excelled at multiple fields, ranging from physics to painting, and from philosophy to physical fitness. He contributed to anatomy, botany and geology, and made a mark in nutrition and health as well. ${ }^{1,2}$ Calling for moderation in diet and regularity in exercise, he would have been a perfect ambassador for good diabetes care and prevention today. Da Vinci combined his genius with hard work. He followed a scientific path in his search for knowledge but embellished it with respect for the arts. ${ }^{2}$ In this way, too, he would be an ideal diabetes care professional, balancing both art and science.

\section{The insulin experience}

Insulin is integral to the management of type 1 diabetes, and many persons with type 2 diabetes. Although it's been in use for nearly a century now, insulin is still disliked and misunderstood by many. This confusion is visible on both sides of the consulting table, among persons with diabetes, as well as their healthcare providers. The terms 'insulin distress", diabetes distress, 'clinical inertia' and 'compassion fatigue' have been used to describe this phenomenon, and other 
Table 1: The seven principles of da Vinci and the insulin experience

\begin{tabular}{|c|c|c|c|}
\hline Principle & Translation & Therapeutic model & Therapeutic implication \\
\hline Curiosita & Curiosity & $\begin{array}{l}\text { Therapeutic patient education, insulin literacy/numeracy, } \\
\text { continuing medical education }\end{array}$ & Keep yourself and your patient updated \\
\hline Dimostrazione & Experience & Clinical experience, demonstration of injection technique & $\begin{array}{l}\text { Increase your experience with insulin, and make your } \\
\text { patient experience it as well }\end{array}$ \\
\hline Sensazione & Sensation & Diabetes-friendly health care, user friendly delivery devices & $\begin{array}{l}\text { Prefer delivery devices which are user-friendly and can be } \\
\text { used by the visually/dexterity challenged }\end{array}$ \\
\hline Sfumato & "the blurring of margins" & Insulin distress, biopsychosocial model & $\begin{array}{l}\text { Listen for symptoms and watch for signs of insulin distress } \\
\text { or psychosocial distress }\end{array}$ \\
\hline Arte/scienza & Art/science balance & Patient centred care, diabetes therapy by the ear & Balance the art and science of diabetes care; master both \\
\hline Corporalita & Body health & Lifestyle modification, providers health, compassion fatigue & Keep yourself and your patient healthy \\
\hline Connesssione & Connections & $\begin{array}{l}\text { Motivation with insulin metaphors, similes, analogies, } \\
\text { motivational interviewing }\end{array}$ & $\begin{array}{l}\text { Learn communication and motivational skills to enhance } \\
\text { insulin use }\end{array}$ \\
\hline
\end{tabular}

related issues. ${ }^{6}$ Well conducted, multinational research has explored the attitude, wishes and needs of people with diabetes, their family members and diabetes care professionals, in relation to insulin. ${ }^{7}$ This has identified shortcomings in communication between patient and provider and pinpointed situations where more attention is required. Thus, it is clear that the insulin experience, as it currently exists, leaves a lot to be desired.

\section{The seven principles}

The basic philosophy that the master followed has been summarised into seven principles: curiosita, dimostrazione, senzazione, sfumato, arte/ scienza, corporalita and connessione (Table 1). ${ }^{2}$ Da Vincian rules have earlier been utilized to craft healthy diets, which may be used to prevent and manage metabolic dysfunction. ${ }^{8}$ We use the seven da Vincian principles in the context of insulin therapy, to describe an insulin experience which would live up to the standards of the maestro.

In concordance with Gelb's editorial style, ${ }^{2}$ we have chosen to retain the Italian words for these principles.

\section{Curiosita}

"An insatiably curious approach to life and an unrelenting quest for continuous learning"

Leonardo da Vinci had an insatiable thirst for learning, which he strived, lifelong, to quench. This curiosita, or curiosity, is the foundation of scientific growth. Every stakeholder in the insulin experience must have curiosita. The diabetes care provider, who suggests, prescribes or explains insulin usage, should be able to satisfy the information needs of the person with diabetes. The concept is known as therapeutic patient education. ${ }^{9}$

The person with diabetes is entitled to know why insulin is needed, how when and where it will be procured, stored, administered and disposed of, and for how long it will be used. This encompasses the concepts of insulin literacy and insulin numeracy. The insulin experience should stimulate these questions in both patient and provider, and ensure that answers are provided as well. An anti-Leonardian insulin experience would be one during which the diabetes care provider discourages or disregards questioning from the patient, and expects non-critical acceptance of her or his prescription.
Curiosita represents continuous learning, and this should reflect in the behaviour of all stakeholders. The diabetes care provider should keep abreast of developments in insulin pharmacology and therapeutics, and analyse them critically, keeping in mind their relevance to the patient in the clinic.

\section{Dimostrazione}

"A commitment to test knowledge through experience, persistence, and a willingness to learn from mistake" ${ }^{2}$

Da Vinci called himself 'discepolo della esperienza' ('disciple of experience'). ${ }^{2}$ The same is true of every diabetes care provider, who acquires knowledge through experience, after having learnt information during education. Insulin counselling and acceptance requires a significant degree of diligence and persistence. Successful insulin motivation is learnt 'on the job', though mistakes.

The Italian word dimostrazione also conveys, to the English language reader, the importance of demonstrating injection technique, ${ }^{10}$ and encouraging self-injection from the very beginning. Had da Vinci been a diabetes care provider, he would have encouraged, or rather championed, the use of realistic toy models ${ }^{11}$ to learn injection technique. He would probably have invented multiple devices for safe storage, transport and disposal of insulin and its ancillaries. He would certainly have experimented with various insulin regimes and preparations, and finally crafted unique individualised therapeutic plans for his patients.

\section{Sensazione}

"The continual refinement of the senses, especially sight, as the means to enliven experience" ${ }^{\prime 2}$

Training, improving and marshalling the senses was on da Vinci's mind when he formulated the principle of sensazione. Da Vinci focused on the eyes as a window to the world. Similarly, the ambience of the diabetes clinic or counselling room is an important part of insulin experience. Every effort must be made to make this as pleasant, salutogenic and person-friendly as possible. ${ }^{12}$ The insulin delivery devices should be visually appealing and should also be user-friendly. Patients with challenges in hearing acuity, visual acuity or motor function should be able to use these devices easily. 
Children and the elderly should be able to navigate the insulin experience on their own.

Had he been involved with diabetes care, Da Vinci would have created delivery devices with cooling/soothing colour combinations, with added features to stimulate the other senses, such as tactile and auditory senses.

\section{Sfumato}

"A willingness to embrace ambiguity, paradox and uncertainty"2

Sfumato is an Italian word which means 'going up into smoke'. Quite often, patients who have been prescribed insulin do not follow the expected script line. In spite of best possible choice of insulin regimens, preparations and delivery devices, glucose levels may remain uncontrolled. Even if guidelines are followed to the minutest detail, not all patients will achieve control. In fact, the percentage of refractory patients tend to be higher in specialist clinics. ${ }^{13}$

Diabetes care, or insulin prescription, is usually a complex affair, characterized by competing biomedical, psychological and social priorities, as well as challenges. ${ }^{14}$ It becomes difficult, therefore, for both prescriber and user to be absolutely objective in their approach to insulin. Insulin distress may be present and may act as a barrier to acceptance or adherence to therapy.

The da Vincian diabetes care provider should not hesitate to explore newer, lesser known dimensions of health, such as psychosocial health and nonpharmacological therapy. Focus on such aspects of diabetes care will actually add value to the insulin experience. This in turn, will help achieve the desired outcomes including good glycaemic control, satisfaction, and quality of life.

\section{Arte/scienza}

"The development of the balance between science and art, logic and imagination. 'Whole brain' thinking"

Da Vinci was unique in that he mastered the arts as well as science. "Study the science of art and the art of science" was what he exhorted his students to do. ${ }^{2}$ This advice is most pertinent for studying the insulin experience. Insulin usage is a science, which demands knowledge of the pathophysiology of diabetes, of its clinical features, of the basic principles of insulin dosage and delivery. At the same time, it is an art (and a challenging one) to motivate the person with type 2 diabetes to accept an injectable treatment, learn the self-management skills required with it, and adhere to a suggested therapeutic plan. ${ }^{14}$ Thus, the diabetes care provider must be skilled at both art and science. She or he should be able to think with both left (analytic) and right (imaginative, big picture) hemispheres. While paying due attention to minute details such as insulin technique and dosage, she or he should also keep the larger picture (patient satisfaction, quality of life) in mind.

\section{Corporalita}

"The cultivation of grace, ambidexterity, fitness and poise"2

Da Vinci was a handsome and athletic man, who maintained himself well. A lover of sports, including walking, riding, swimming and fencing, he followed a healthy vegetarian diet, and counselled against stress and anger. ${ }^{2}$ The same advice is found in the triad of non-pharmacological diabetes care: physical activity/exercise, nutrition therapy and stress management. Corporalita is important for both the patient with diabetes, and her or his provider.

The insulin experience will offer required dividends only if it occurs in a setting of optimised non-pharmacological health interventions. A person with poor physical conditioning, following an unhealthy diet, and under psychosocial stress, will not respond to insulin as expected. Similarly, the diabetes care provider who does not follow a healthy lifestyle, will not be able to set good example for the patient. A provider who experiences compassion fatigue, ${ }^{15}$ or physical fatigue for that matter, will not be at her or his best while counselling, and may not be able to create the ideal insulin experience.

\section{Connessione}

"A recognition of, and appreciation for, the interconnectedness of all things and phenomena. System thinking"2

Da Vinci continually searched for patterns and connections around him. He used seemingly disconnected facts and figures to create unified objects and theories. The same is done with modern diabetes care, where analogies, metaphors and similes are used, in a person-centric manner, to explain the importance of insulin. ${ }^{16,17}$ While every diabetes care professional has her or his style, the spectrum of insulin-related analogies is humungous. A Leonardian approach to motivate interviewing for insulin would include relevant examples from local culture, religion and environment. These would strengthen the importance of good health, and of proactive intervention, using insulin, to achieve good health.

\section{Summary}

It is important to understand the basic principles of success, as followed by Leonards da Vinci curiosita, dimostrazione, senzazione, sfumato, arte/ scienza, corporalita and connessione. Once internalised, they can be used to help improve health outcomes in people with diabetes. $\square$
1. Leonardo da Vinci Biography. Available at: www.biography.com/ people/leonardo-da-vinci-40396 (accessed on 21 June 2018).

2. Gelb MJ, Think like da Vinci. London, Harper Element: 2009.

3. The Discovery and Early Development of Insulin. Hughes

(Elizabeth) Papers. Available at: https://insulin.library.utoronto.ca/ islandora/object/insulin\%3Ahughes (accessed on 21 June 2018).

4. Ogurtsova K, da Rocha Fernandes JD, Huang Y, et al. IDF Diabetes Atlas: Global estimates for the prevalence of diabetes for 2015 and 2040. Diabetes Res Clin Pract. 2017;128:40-50.

5. Lipska KJ, Yao X, Herrin J, McCoy RG, et al. Trends in drug utilization, glycemic control, and rates of severe hypoglycemia, 2006-2013. Diabetes Care. 2017:40:468-75.

6. Kalra S, Verma K, Singh YB. Management of diabetes distress. J Pak Med Assoc. 2017;67:1625-7.
7. Peyrot M, Burns KK, Davies M, et al. Diabetes Attitudes Wishes and Needs 2 (DAWN2): a multinational, multi-stakeholder study of psychosocial issues in diabetes and person-centred diabetes care. Diabetes Res Clin Pract. 2013:99:174-84.

8. Kalra S. The da Vincian diet. J Pak Med Assoc. Accepted for publication, 2018.

9. Assal JP, Mühlhauser I, Pernet A, et al. Patient education as the basis for diabetes care in clinical practice and research. Diabetologia. 1985;28:602-13.

10. Tandon N, Kalra S, Balhara YS, et al. Forum for injection technique (FIT), India: The Indian recommendations 2.0, for best practice in insulin injection technique, 2015. Indian J Endocrinol Metab. 2015:19:317-31.

11. Kalra S, Chugh S, Dinakaran P. Diabetes and play therapy. Journal of Social Health and Diabetes. 2014;2:40.
12. Kumar KP, Raghupathy P, Kalra S. Diabetes-friendly environments for children with diabetes. Indian J Endocrinol Metab. 2015;19(Suppl 1):S1.

13. Kalra S, Talwar V. Refractory diabetes: Focus on the obvious. J Pak Med Assoc. 2017:67:146-7.

14. Kalra S, Sridhar GR, Balhara YP, et al. National recommendations: Psychosocial management of diabetes in India. Indian J Endocrinol Metab. 2013;17:376.

15. Bhutani J, Bhutani S, Balhara YP, Kalra S. Compassion fatigue and burnout amongst clinicians: a medical exploratory study. Indian J Psychol Med. 2012;34:332.

16. Kalra S, Gupta Y. Addressing insulin misperceptions (AIM)-part 2 I Pak Med Assoc. 2016;66:229-31.

17. Kalra S, Gupta Y. Addressing insulin misperceptions (AIM)-part 1. J Pak Med Assoc. 2016;66:115-7. 